\title{
Influence Mechanism of Main Roof Height on Surrounding Rock Stability of Gob-Side Entry Driving
}

\author{
Hai-ging SHUANG, Shu-gang LI, Gao-feng CHEN, Peng XIAO, Liang-chang SHEN, Ki-il SONG
}

\begin{abstract}
The main roof directly affects the stress environment and the control effect of the surrounding rock of gob-side entry driving. A mechanical model of the surrounding rock of gob-side entry driving was established to analyze the influence mechanism of different main roof heights on the surrounding rock stability of the roadway under similar geological conditions. In addition, the influences of the main roof heights on the stress distribution of the surrounding rock were qualitatively analyzed. A quantitative analysis of the stress and deformation distribution characteristics of the surrounding rock were conducted by Universal Distinct Element Code (UDEC) when the heights were 0,5 , and $10 \mathrm{~m}$ based on the actual geological conditions. Results show that waste rocks in the caving zone and damaged immediate roof could provide four different stress combinations to key rock block, which is affected by the main roof height and other related parameters. With the increase in the main roof height, the hinged stress between the key rock blocks and the plastic damage area of the physical coal wall are reduced, the damage range of immediate roof gradually increases, and the vertical stress of narrow coal pillars first increases to $5.22 \mathrm{MPa}$ and then remains at approximately $1.92 \mathrm{MPa}$. Therefore, the supporting strength of roof and the physical coal wall should be enhanced. Research results are successfully applied in the Yanjiahe Coal Mine. The conclusions provide significant theoretical guidance for controlling surrounding rock stability of the roadway under similar conditions.
\end{abstract}

Keywords: gob-side entry driving; main roof height; numerical simulation; surrounding rock stability

\section{INTRODUCTION}

In recent years, numerous mining areas in China have encountered resource depletion and tension of the working faces with the increase in the intensity of coal resources. Gob-side entry driving with narrow coal pillar is extensively used in China. This roadway arrangement can improve the recovery rate of coal resources, shorten the preparation time of excavation roadway, and prolong the service life of coal mines [1-3].

The stress environment in the surrounding rock of gob-side entry driving is compared with the conventional working face mining roadway. Findings show that the deformation control of roadway surrounding rock is complicated. Therefore, effectively controlling the deformation of the surrounding rock of roadway has become the key influencing factor of its rapid development [4-6]. Previous studies have emphasized two main influencing factors: subjective and objective factors [6]. The former mainly refers to the natural factors that are difficult to change, such as coal/rock type and geology; the latter refers to factors that can be artificially changed, such as yield pillar width and key supporting technology.

The main roof controls the movement of the overlying strata and breaks into the key rock blocks above the mining roadway at the end of the working face. Therefore, the stability of the key rock blocks directly determines the stress environment of the roadway. Preliminary results demonstrate that the main roof height is the most important factor in the stability of surrounding rocks [6]. The thickness of immediate roof often increases and decreases in a coal mine, and roadway deformation considerably differs in the engineering practice. Thus, the main roof height should be studied for surrounding rock stability.

This study examines a core problem in the influence mechanism of main roof height on the surrounding rock stability of gob-side entry driving and aims to establish the foundation for further numerical analysis and engineering practice.

\section{STATE OF THE ART}

Key rock block directly influences the stability of the large surrounding rock structure of gob-side entry driving and further affects the control effect of the surrounding rock of the roadway. Therefore, stability of the main roof is critical to the safety production of working face, which is considered to be a subjective factor. With the rapid development of bolt-supporting technology in gob-side entry driving in China, the supporting technologies are also important research objects and are regarded as objective factors [7]. Scholars used various methods to study the subjective and objective factors that affect surrounding rock stability. The mechanisms of surrounding rock stability were analyzed by theoretical analysis. For example, Li et al. [8] explored the stability principle of large and small structures by theoretical analysis, in which the main roof was part of large structures, and the control of small structure technology was proposed. Bai et al. [9, 10] studied the stability of an arc triangular block at the ends of working face; the supporting technology, as well as the width and location of narrow pillar, were analyzed and extensively used according to the stability. Feng et al. [11] studied the influence mechanism of the caving characteristic and roof structure on roadway stability, and the optimal position for the roadway was identified and successfully applied in the Huainan Mining Areas. Li et al. [12] studied the balance conditions among the key rock blocks above gobside entry, and roadside support resistance was quantitatively provided and applied in the Huainan Mining Area. Zhang et al. [13] studied the stability of retained gob-side entry in four different conditions: mining depth, support strength, area of gob-side hanging roof, and length of cantilever roof block, among which, the last factor was considered the most important. In the preceding studies mentioned, mechanical models of the surrounding rock stability of gob-side entry driving are established. In addition, the balance conditions of key rock blocks and the influences of stresses on the 
surrounding rock stability are analyzed. However, the models focus on the analysis of balance conditions and fail to conduct a single-factor analysis. The models differ due to simplified conditions and boundaries. The main roof height is a fixed parameter in processes, which is not conducive to the analysis of the influence of main roof height change on the surrounding rock stability under the same geological conditions.

Numerical simulation methods were applied in the analysis of the influence mechanism to be close to the actual surrounding rock stress conditions. For example, Li et al. [14] studied the surrounding rock deformation characteristics and support requirements of gob-side entry driving under composite roof conditions, and a technology for reasonably controlling surrounding rocks was proposed. Wang et al. [15] analyzed the deformation characteristics of a typical deep gob-side entry, and a technology for rationally controlling surrounding rocks combined with actual conditions was introduced. Wang et al. [16] analyzed the influence of the fracture position of main roof on the surrounding rock stability of gob-side entry driving by comprehensive analysis; the result indicated that the roadway should not be below the fracture line of the main roof. Su et al. [17] studied two main difficulties in maintaining surrounding rock stability in actual geological conditions, and the technology of "roofing control and wall strengthening" was proposed. Yang et al. [18] studied soft roof failure mechanism and the supporting method for gob-side entry retaining in a gently inclined coal seam; bolt parameters were optimized and analyzed. In the preceding studies mentioned, mechanical models are not established according to different geological conditions, and Fast Lagrangian Analysis of Continua (FLAC) [14, 15] and Universal Distinct Element Code (UDEC) [16-18] are used to quantitatively analyze the stress and strain distribution characteristics of surrounding rock. However, FLAC is conducive to analyzing stress distribution characteristics, while UDEC is conducive to analyzing the characteristics of the region and the broken position of main roof. These programs create limitations of the numerical simulation to analyze the mechanism; however, theoretical analysis, multiple programs, and mechanical models could be used for comprehensive analysis to reduce these limitations.

Therefore, in view of the preceding problems mentioned, this study focused on the influence mechanism of main roof height on surrounding rock stability. The effect of main roof height on the stress conditions of key rock block B was qualitatively analyzed by establishing a mechanical model of the surrounding rock of gob-side entry driving in a fully-mechanized topcoal caving working face. The basic numerical simulation model was established based on the geological conditions of the 8105 working face of the Yanjiahe Coal Mine, which was used to conduct a quantitative analysis of the stress and displacement distribution characteristics of the surrounding rock of gob-side entry driving under different main roof heights by UDEC. The key supporting technologies for the surrounding rock stability under different main roof heights were proposed. The research results were successfully applied in the 8105 working face. Therefore, the conclusions could provide significant theoretical guidance for controlling surrounding rock stability of the roadway under similar conditions.

The remainder of this study is organized as follows. Section 3 establishes the mechanical and numerical models. Section 4 discusses the qualitative and quantitative analyses of the stress and deformation distribution characteristics of surrounding rock through the models and engineering application. Finally, Section 5 concludes the study.

\section{METHODOLOGY}

The engineering model of surrounding rock should be simplified into a structural mechanical model in the fullymechanized top-coal caving working face to determine the influence mechanism. The balance conditions of the key rock blocks above roadway are qualitatively analyzed in the model, and the influences of the main roof height factors on the surrounding rock stability are evaluated. The distribution laws of stress and displacement of surrounding rock under different main roof heights are analyzed by numerical simulation based on the theoretical analysis and the actual geological conditions of the Yanjiahe Coal Mine, which establishes the foundation for the influence mechanism research.

\subsection{Mechanical Analysis of Key Rock Block 3.1.1 Mechanical Model Establishment}

The main roof movement directly influences surrounding rock stability of the roadway. Gob-side entry driving with narrow coal pillars is performed in the goaf along the last working face after the overlying strata of the working face is stable [9]. The mechanical model of the surrounding rock of gob-side entry driving in the fully-mechanized top-coal caving working face is shown in Fig. 1 [6].

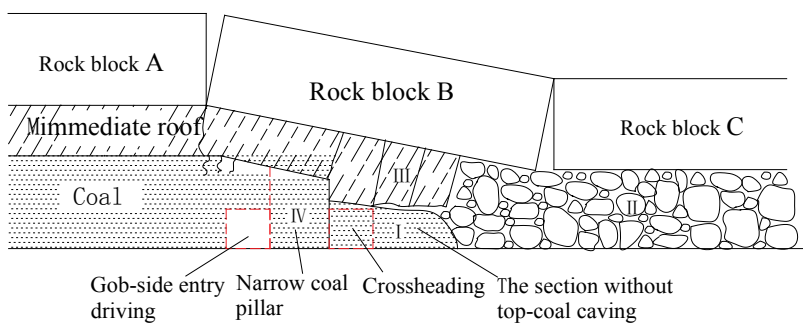

Figure 1 Mechanical model of the surrounding rock of gob-side entry driving in the fully-mechanized top-coal caving working face

The stress analysis of key rock block B was conducted with the following parameters [6, 10]: the resultant shear force and the horizontal thrust of key rock block $\mathrm{A}$ on key rock block $\mathrm{B}$ are $R_{A B}$ and $T_{A B}$, respectively; the resultant vertical shear force and the horizontal thrust of key rock block $\mathrm{C}$ on key rock block $\mathrm{B}$ are $R_{B C}$ and $T_{B C}$, respectively; the dead load of the soft stratum above block B is $F_{R}$; the dead load resultant force of block B is $F_{Z}$; the support force of goaf waste rock to block $\mathrm{B}$ is $F_{G}$; the support force of the damaged immediate roof in the section without top-coal caving to block B is $F_{D}$; the support force of the immediate roof in the narrow coal pillar to block $\mathrm{B}$ is $F_{S}$; the support force of the immediate roof of the physical coal wall to block B 
is $F_{M}$; the rotation angle of block $\mathrm{B}$ is $\theta$; and the fracture position of the main roof has $x_{0}$ distance from the physical coal wall. The stress situations of block B are shown in Fig. 2.

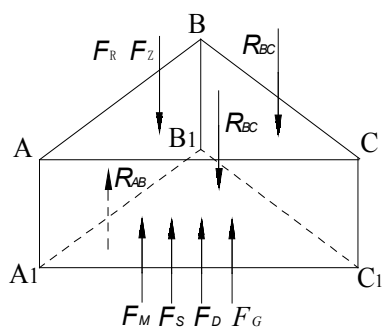

(a) Vertical

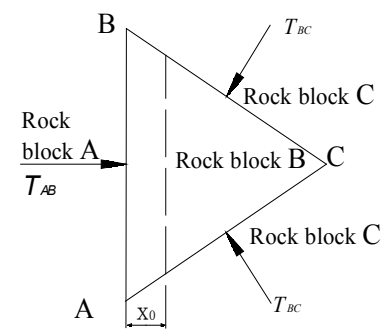

(b) Horizontal
Figure 2 Stress analysis of key rock block $B$

\subsubsection{Balance Condition of Key Rock Block B}

Rock block B should horizontally and vertically achieve balance of stress after its stability to maintain a balanced state in its surrounding rock.

(1) Vertical:

$\sum F_{y}=0$,

$R_{A B}+F_{M}+F_{D}+F_{G}-2 R_{B C}-F_{R}-F_{Z}=0$,

(2) Horizontal:

$\sum F_{x}=0$,

$T_{A B}-2 T_{B C} \cos \alpha=0$,

where $a$ is the base angle of key rock block B.

(3) The conditions for key rock blocks B and A to lose stability are
$T_{\mathrm{AB}} \tan \varphi \geq R_{\mathrm{AB}}$,

$T_{\mathrm{AB}} /\left(L_{1} a\right) \leq \eta \sigma_{\mathrm{C}}$,

where $\tan \varphi$ stands for the friction factor between the two rock blocks; $T_{\mathrm{AB}} /\left(L_{1} a\right)$ stands for the average crushing stress between the two rock blocks; $L_{1}$ stands for the length of key rock block $\mathrm{B}$; $a$ stands for the action parameters between key rock blocks $\mathrm{B}$ and $\mathrm{A}, \mathrm{C} ; \eta$ stands for the special coefficient of the stress analysis between the two rock blocks; and $\sigma_{C}$ stands for the compressive strength of rock block B [19].

\subsection{Numerical Model Establishment}

Gob-side entry driving with narrow coal pillars is adopted in the Yanjiahe Coal Mine in China due to the difficulties in working face connection and support technique to surrounding rock. A numerical model, $200 \mathrm{~m}$ long and $114 \mathrm{~m}$ high, was created using the numerical simulation analysis software UDEC2D4.0, in accordance with the bore $\log$ of the borehole X4 in the No. 8105 working face. The working face's mining height was 7.0 $\mathrm{m}$, the dip angle was $0^{\circ}$, the horizontal ground stress was 9.40 MPa, the vertical stress was $14.10 \mathrm{MPa}$, and the side pressure coefficient was 0.67 . The vertical displacement of the lower boundary of the model was fixed, and the horizontal displacements of its left and right boundaries were fixed. The Mohr-Coulomb model was used to derive the constitutive relation of the surrounding rock. The parameters for different rocks tested are shown in Tab. 1. The more detailed steps were described in the literature [6]. The main roof height and strength, length of key rock block, and fracture positions were calculated by using orthogonal experimental method. Among them, the main roof height mostly influenced the surrounding rock stability $[6,20]$.

Table 1 Parameters for different rocks tested

\begin{tabular}{|c|c|c|c|c|c|}
\hline Lithology & Bulk modulus / GPa & Modulus of igidity / GPa & Friction $/{ }^{\circ}$ & Cohesion / MPa & Thickness / m \\
\hline Coarse andstone & 11 & 9 & 36 & 4.0 & 7 \\
\hline Sandy mudstone & 16 & 12 & 32 & 3.5 & 20 \\
\hline Siltstone & 20 & 16 & 33 & 6.0 & 10 \\
\hline Siltstone & 20 & 16 & 33 & 6.0 & 6 \\
\hline $5^{-1}$ Coal & 8 & 6 & 28 & 1.5 & 3 \\
\hline Mudstone & 6 & 5 & 28 & 4.0 & 2 \\
\hline Sandy mudstone & 16 & 12 & 32 & 3.5 & 2 \\
\hline $5^{-2}$ Coal & 8 & 6 & 28 & 1.5 & 2 \\
\hline Mudstone & 6 & 5 & 28 & 4.0 & 3 \\
\hline Sandy mudstone & 16 & 12 & 32 & 3.5 & 3 \\
\hline Siltstone & 20 & 16 & 33 & 6.0 & 3 \\
\hline Sandy mudstone & 16 & 12 & 32 & 3.5 & 8 \\
\hline Siltstone & 20 & 16 & 33 & 6.0 & 4 \\
\hline 7Coal & 8 & 6 & 28 & 1.5 & 2 \\
\hline Mudstone & 6 & 5 & 28 & 4.0 & 2 \\
\hline Sandy mudstone & 16 & 12 & 32 & 3.5 & 1.5 \\
\hline 8 Coal & 8 & 6 & 28 & 1.5 & 7 \\
\hline Siltstone & 12 & 10 & 38 & 7.0 & 28.5 \\
\hline
\end{tabular}

Three different schemes are set to analyze the effect of main roof height on the surrounding rock stability of gob-side entry driving. The distances between the main roof and the coal seam roof in schemes 1,2, and 3 are set as 0,5 , and $10 \mathrm{~m}$, respectively. Scheme 3 is consistent with the actual conditions in the 8105 fully-mechanized caving face $[6,16]$. Supporting parameters are determined according to engineering application, and these parameters are the same in the three schemes. The rail transport advancing section in the 8105 fully-mechanized 
top-coal caving working face is a $4000 \times 3000 \mathrm{~mm}$ rectangle, and this section adopted the joint scheme of "high-strength screw-thread steel resin anchor rod + high preload + cable supplement support + beam net". The distance of the section without top-coal caving is $7 \mathrm{~m}$. During the simulation process, the last working face is excavated and balanced first before gob-side entry driving. Corresponding stress and displacement monitoring points are arranged throughout the simulation. In the proceeding discussion, the distribution laws of stress and displacement of the surrounding rock of gob-side entry driving under different schemes are comparatively analyzed.

\section{RESULT ANALYSIS AND DISCUSSION}

This section quantitatively analyzes the influence mechanism of main roof height on the surrounding rock stability base on the mechanical model in Section 3.1. The numerical simulation model in Section 3.2 and the stress distribution, plastic zone, and deformation of roadway rock are analyzed when the main roof heights are 0,5 , and $10 \mathrm{~m}$, as shown in Subsections 4.1 to 4.3, respectively. The key supporting technologies under different conditions are analyzed based on the results. The research results are used in the Yanjiahe Coal Mine, as shown in Section 4.5.

\subsection{Effect of Main Roof Height on the Stress Conditions of Key Rock Block B}

Section 3.1 indicates that many factors influence the stability of key rock block B. Among these factors, the main roof height exhibits direct influences by $F_{D}, F_{G}$, and $\theta$. An independent analysis is conducted in the following text. The main roof height of the working face in the fully-mechanized top-coal caving working face is mainly influenced by coal-cutting, coal-caving, and immediate roof thicknesses.

(1) The support force of the damaged immediate roof to key rock block $\mathrm{B}$ is $F_{D}$.

Only coal exploitation occurs, but no coal caving exists at 2-3 supports of the working face ends. In the cross-heading of the original working face, a total of $w$ (approximately $7 \mathrm{~m}$ ) coal seam that has coal exploitation but no top-coal caving is obtained. The immediate roof in the section without top-coal caving may possess a support force to key rock block B.

1) The settlement of key rock block B in the section without top coal caving is

$$
h_{1}=\left(x_{0}+w\right) \sin \theta \text {, }
$$

2) The compression of immediate roof in the section without top coal caving is

$s_{1}=\frac{h_{1}-\left[m+H_{l}-\left(m-m_{1}\right) K_{m}-H_{l}\left(K_{l}-1\right)\right]}{\left(m-m_{1}\right) K_{m}+H_{l} K_{l}}$,

where $m$ is the coal-mining width, $m_{1}$ is the coal-cutting thickness in the fully-mechanized top-coal caving working face, $K_{m}$ is the bulking coefficient of coal mass,
$H_{l}$ is the thickness of immediate roof, and $K_{l}$ is the bulking coefficient of the immediate roof.

3) The support force of the immediate roof in the section without top-coal caving to key rock block B is $F_{D}$.

When $s_{1} \leq 0$, the immediate roof is not compressed, and no support force is generated after the rotating settlement of key rock block B.

When $s_{1}>0$, the immediate roof is compressed, and a support force is generated after the rotating settlement of key rock block B. The support force $\left(f_{d}\right)$ generated by the immediate roof per unit area is

$f_{d}=K_{D} s_{1}$

where $K_{D}$ is the supporting strength of the immediate roof in the section without top-coal caving to key rock block B.

$F_{D}=\int_{x_{0}}^{x_{0}+w} f_{d}\left[\frac{-2}{\tan \alpha}\left(x-L_{2}\right)\right] \mathrm{d} x$,

(2) The support force of waste rocks in the caving zone is $F_{G}$.

1) The goaf height is

$h_{2}=m-\left[m(1-\eta) K_{m}+H_{l}\left(K_{l}-1\right)\right]$,

where $\eta$ is the percentage recovery of the working face.

2) The rotating settlement of key rock block B close to the goaf side bottom is

$s_{x}=x \sin \theta$,

3) The compression ratio of key rock block B to waste rocks underneath is $s_{y}$.

If key rock block B has no settlement at the fracture position, then the compression ratio of the caving waste rocks underneath is

$s_{2}=\frac{s_{x}-h_{2}}{m(1-\eta) K_{m}+H_{l} K_{l}}$

4) The support force of caving waste rocks to key rock block B is $F_{G}$.

When $s_{2} \leq 0$, key rock block B is not yet in contact with waste rocks or only comes in contact with waste rocks after the rotating settlement of key rock block B, that is, $F_{G}=0$.

When $s_{2}>0$, key rock block B comes in contact with waste rocks, and these rocks are compressed to produce a support force after the rotating settlement of key rock block B. The support force $\left(f_{g}\right)$ produced by waste rocks per unit area is

$f_{g}=K_{G} s_{2}$,

where $K_{G}$ is the supporting strength of caving waste rocks in the goaf to key rock block B. 


$$
F_{G}=\int_{x_{0}+w}^{L_{2} \cos \theta} f_{g}\left[\frac{-2}{\tan \alpha}\left(x-L_{2}\right)\right] \mathrm{d} x,
$$

Overall, $s_{1}$ and $s_{2}$ may have four combinations under different main roof heights: (a) $s_{1} \leq 0$ and $s_{2}>0$; (b) $s_{1} \leq 0$ and $s_{2} \leq 0$; (c) $s_{1}>0$ and $s_{2}>0$; and (d) $s_{1}>0$ and $s_{2} \leq 0$. These combinations correspond to four different stress conditions for the balanced condition of key rock block B. The rotation angle of key rock block B is closely related to the compression ratios of the immediate roof in the section without top-coal caving and waste rocks in the goaf. The analysis of $s_{1}$ and $s_{2}$ coal-mining width $(\mathrm{m})$ indicates that the coal-cutting thickness in the fullymechanized top-coal caving working face $\left(m_{1}\right)$ and the thickness of immediate roof $\left(H_{l}\right)$ directly determine the main roof height. By contrast, the bulking coefficient of coal mass $\left(K_{m}\right)$, the bulking coefficient of immediate roof
$\left(K_{l}\right)$, and the percentage recovery of the working face $(\eta)$ determine the effect of main roof height on the surrounding rock stability in roadway. Therefore, changes in main roof height cause different stress conditions of key rock block $\mathrm{B}$, thus resulting in different stress and displacement distribution laws of surrounding rock.

\subsection{Stress Distribution Law of the Surrounding Rock of Gob-Side Entry Driving 4.2.1 Stress Field Distribution Law of Surrounding Rock}

The stress condition of main roof determines the stress features of the overlying strata in gob-side entry driving and influences the stress and plastic zone distribution laws of surrounding rock. The stress and plastic zone distribution laws of surrounding rock in three schemes are shown in Figs. 3 and 4, respectively.

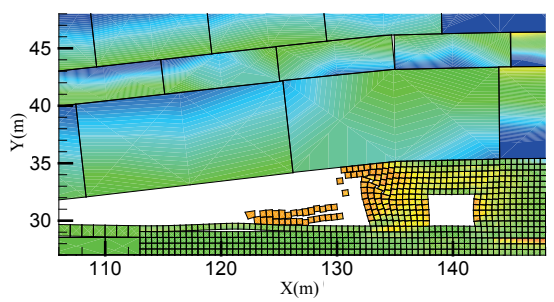

(a) Scheme 1

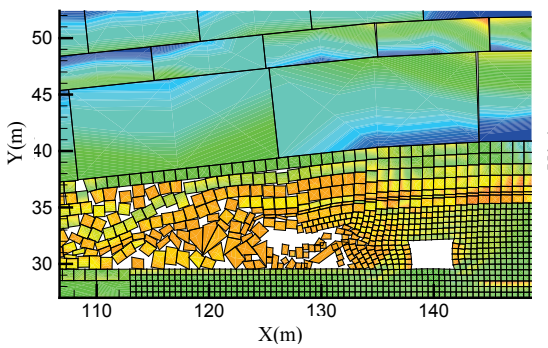

(b) Scheme 2

Figure 3 Stress distribution law of surrounding rock

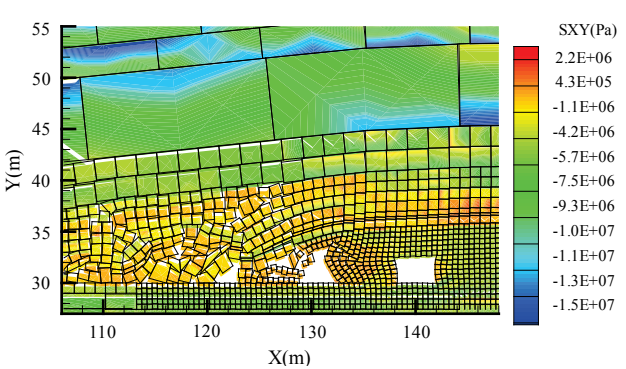

(c) Scheme 3

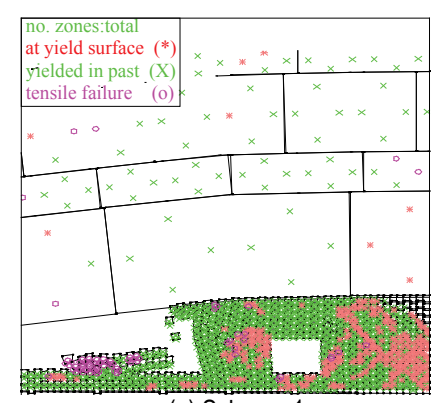

(a) Scheme 1

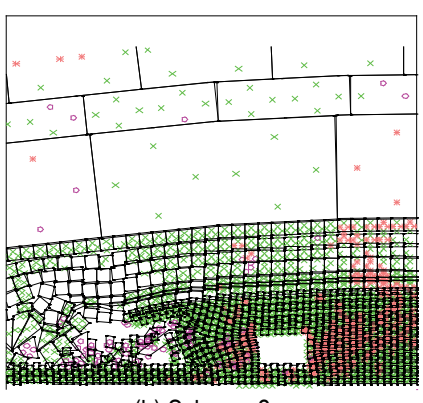

(b) Scheme 2

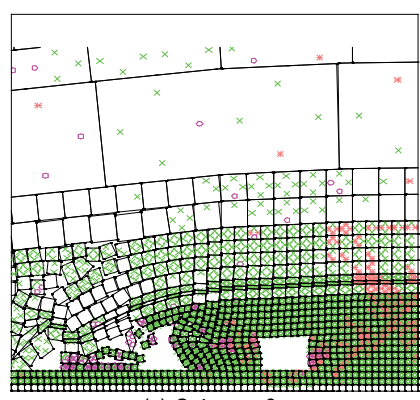

(c) Scheme 3

Figure 4 Plastic zone distribution law of surrounding rock

Figs. 3 and 4 depict that stresses on surrounding rock rapidly redistribute after the recovery of the last working face. Key rock block B loses stability in the goaf and produces a rotating settlement to achieve stress balance. Key rock block B forms a hinged structure with key rock blocks $\mathrm{A}$ and $\mathrm{C}$. This hinged structure may be influenced by $F_{G}, F_{D}, F_{S}$, and $F_{M}$. The stress distribution laws of surrounding rock vary under different main roof heights.

In scheme 1 , when the main roof height is $0 \mathrm{~m}$ (no immediate roof), the stresses on key rock block B are only $F_{S}$ and $F_{M}$, and the remaining stresses are supplied by key rock blocks $\mathrm{A}$ and $\mathrm{C}$ to provide a balanced state to block B. Consequently, the stress concentration region among key rock blocks is large in size and has a high stress value, accompanied with large-scale plastic damages at the physical coal wall at hinge joints. The entire roadway is in the stress reduction zone, and the narrow coal pillars suffer plastic damages during the balancing of stresses. However, the overall deformation of surrounding rock is within the allowable range under reasonable anchor (cable) support conditions.
In scheme 2, when the main roof height is $5 \mathrm{~m}$, goaf waste rocks can support key rock block $\mathrm{C}$ by random arrangement. The support force can be transmitted to key rock block B. With $F_{G}, F_{D}, F_{S}$, and $F_{M}$, the stress concentration region between key rock blocks A and $\mathrm{B}$ narrows, and the stress peak reduces. Influenced by the overlying load, the immediate roof suffers large-scale plastic damages, especially below the hinge joints of key rock blocks. The plastic damage scope at the physical coal wall relatively reduces.

In scheme 3, when the main roof height is $10 \mathrm{~m}$, the immediate roof presents a disordered arrangement in the goaf, with collapsing narrow coal pillars that can directly support key rock blocks $\mathrm{B}$ and $\mathrm{C}$. The stress concentration region at the hinge joint between blocks $\mathrm{A}$ and $\mathrm{B}$ narrows, and the stress peak reduces. The immediate roof above the physical coal wall suffers large-scale damages, which can release concentrated stress on the surrounding rock to some extent. Therefore, plastic damage regions at the physical coal wall scatter in small scales. 
Overall, with the increase in the main roof height, the rotating settlement and rotation angle of key rock block B decrease and stabilize, which can be attributed to the stresses from residual coals, waste rocks, and damaged immediate roof in the goaf in the last working face. The stress concentration at hinge joints of key rock blocks relieves and gradually stabilizes. Moreover, stresses are relieved during the transmission process due to the damages of the immediate roof above the physical coal wall and the roadway, finally narrowing the plastic damage region at the physical coal wall and the roadway.

\subsubsection{Vertical Stress Characteristics of Narrow Coal Pillar}

The stress characteristics of narrow coal pillars can reflect the stability at the narrow coal side during the balancing of stress on the surrounding rock of gob-side entry driving. Before roadway driving, three monitoring points are set at $2 \mathrm{~m}$ in the middle of narrow coal pillars to seam floor to record the vertical stress changes during the roadway driving. The vertical stress of narrow coal pillars is the mean of three monitoring points. The vertical stress characteristics of narrow coal pillars are shown in Fig. 5.

Fig. 5 demonstrates that the vertical stress characteristics of narrow coal pillars under different schemes significantly vary. After the recovery of the last working face, the overlying strata gradually stabilize, and the narrow coal pillars are located in a plastic region with relatively small vertical stress. When stresses on surrounding rock rapidly redistribute until reaching the balanced state, the surrounding rock stress on the immediate roof in scheme 1 is directly transmitted by the main roof. Therefore, the average vertical stress of narrow coal pillars rapidly reduces until reaching the balanced state (5.22 $\mathrm{MPa})$. Schemes 2 and 3, which have a collaborative effect of main and immediate roofs after roadway driving, the average vertical stress of narrow coal pillars first increases and then decreases until reaching the balanced state. The stress peaks are 13.59 and $11.60 \mathrm{MPa}$, and the balance stresses are 1.73 and 2.12 $\mathrm{MPa}$.

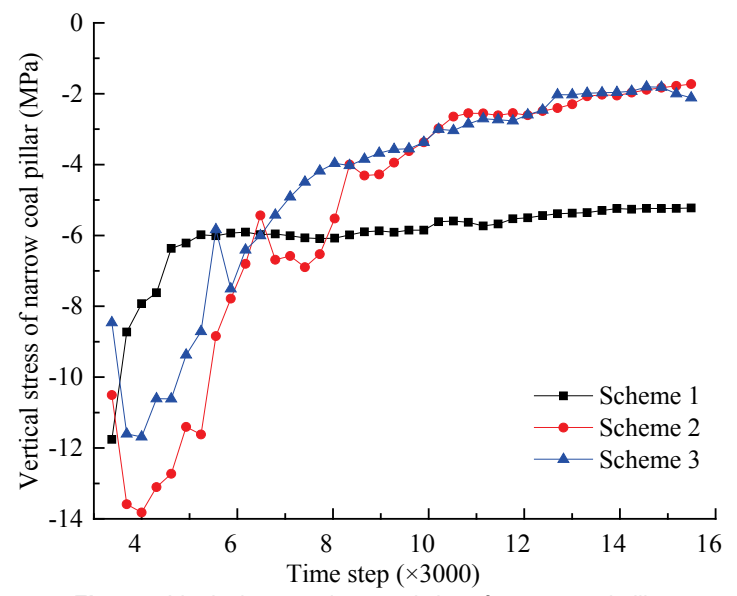

Figure 5 Vertical stress characteristics of narrow coal pillars

\subsection{Deformation Characteristics of Surrounding Rock 4.3.1 Resultant Displacement of Surrounding Rock}

The surrounding rock stresses in roadway have different characteristics under different main roof heights, thus resulting in various deformation characteristics of the surrounding rock. The displacement field distribution laws of surrounding rock under different schemes are shown in Fig. 6.

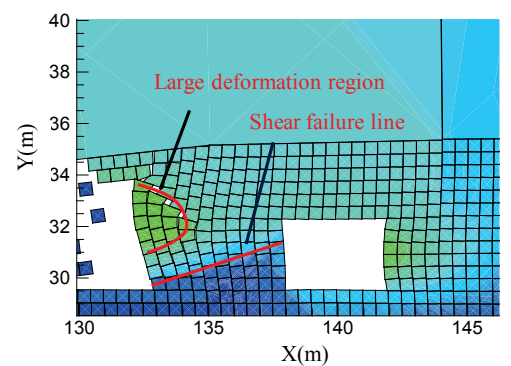

(a) Scheme 1

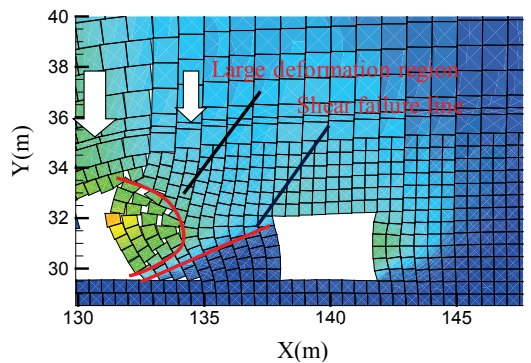

(b) Scheme 2

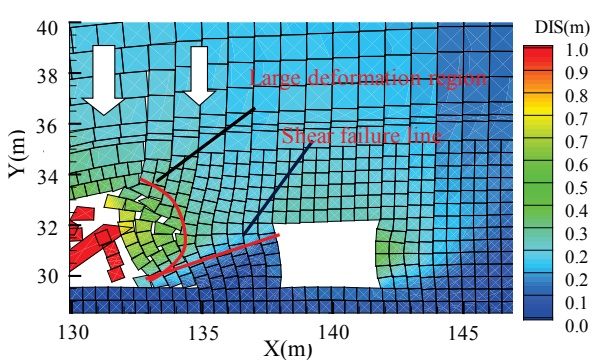

(c) Scheme 3

Figure 6 Distribution law of resultant displacement field of surrounding rock

In Fig. 6, different stress fields in surrounding rock cause different deformations of narrow coal pillars and the surrounding rock. After key rock block B breaks and retains settlement, surrounding rock is deformed to different extents: at two sides and the roof. The bottom heaving is relatively small. The overall damage degree of narrow coal pillars, as well as the displacement between the upper and lower positions of one narrow coal pillar, are all different, thereby showing an evident "shear failure line".

In Fig. 6(a) (scheme 1) without immediate roof, key rock blocks break and then present a rotating settlement that can directly act on narrow coal pillars. A small large deformation region exists above the goaf close to narrow coal pillars, and the angle of the "shear failure line" is relatively small.

In Fig. 6(b) (scheme 2), the immediate roof at different positions above narrow coal pillars is damaged to different extents due to the rotating settlement of key rock block B. This phenomenon causes out-sync settlement of the immediate roof and increases the deformation region above narrow coal pillars and the angle of "shear failure line" below the narrow coal pillars.

In Fig. 6(c) (scheme 3), the situation is basically the same as that in scheme 2 . The difference in this scheme is that with the thickening of immediate roof, the out-sync settlement displacement of the immediate roof increases, and the large deformation region above narrow coal 
pillars continuously expands, accompanied with continuous enlargement of the "shear failure line" angle.

\subsubsection{Deformation Analysis of Surrounding Rock}

The deformation of surrounding rock is often measured by double cross method. Four monitoring points are set surrounding the roadway [3]. The deformations of surrounding rock under different schemes are shown in Fig. 7.

Fig. 7 shows that the deformation process of surrounding rock mainly includes fast, slow, and stable deformation stages. The relative deformation characteristics of surrounding rock under different schemes are different. In scheme 1, the relation deformations at two sides and roof-floor after the fast deformation stage are 161.84 and $74.20 \mathrm{~mm}$, respectively, while the relative deformations in the stable deformation stage are 212.19 and $103.41 \mathrm{~mm}$, respectively. In scheme 2 , the relative deformations after the fast deformation stage are 240.56 and $128.91 \mathrm{~mm}$, and the relative deformations in the stable deformation stage are 368.08 and $230.33 \mathrm{~mm}$. In scheme 3 , the relative deformations after the fast deformation stage are 254.15 and 139.11 $\mathrm{mm}$, and the relative deformations in the stable deformation stage are 359.90 and $222.88 \mathrm{~mm}$. Therefore, the deformation of surrounding rock mainly occurs during the fast deformation stage and at two sides. In the three schemes, the relative deformations of two sides and rooffloor during the stable deformation stage are $205 \%, 160 \%$, and $161 \%$, respectively. This finding and the illustration in Fig. 7 indicate that the relative deformation of two sides is mainly at the physical coal wall and that of rooffloor is mainly at the roof.

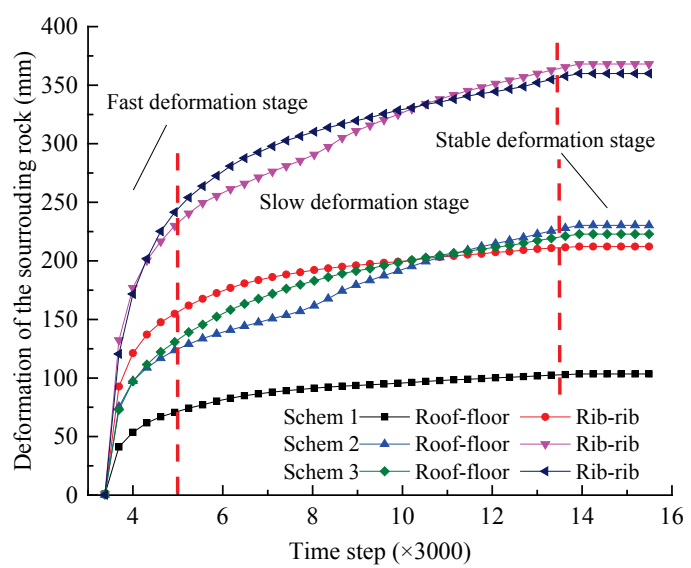

Figure 7 Deformation of surrounding rock

\subsection{Key Supporting Technologies for Controlling Surrounding Rock Stability}

The surrounding rock strength of small structures in roadway can affect the stress and displacement characteristics of large structures in the overlying strata, and supporting technologies of small structures directly determine the surrounding rock stability [8, 9]. Key supporting technologies to surrounding rock are proposed according to stress distribution laws under different main roof heights.
(1) With respect to the stress-strain features of surrounding rock without immediate roof (scheme 1), the vertical stresses on key rock block B mainly include the supporting forces from the overlying load, dead load, narrow coal pillars, and physical coal wall, as well as the hinging stress among key rock blocks. The rotating settlement of key rock block B results in narrow coal pillars at the plastic region, and the place below the hinging effect between key rock blocks A and B increase the stress concentration region at the physical coal wall. The supporting strength to roof with strong key rock blocks and perfect integrity is selected according to the strength of immediate roof. However, supporting technologies are necessary at narrow coal pillars and physical coal wall with large stress and plastic region. The anchor length at physical coal wall should be increased to transmit concentrated stress from surrounding rock to deep places of the physical coal wall.

(2) With respect to the stress-strain features of surrounding rock under a low main roof height (scheme 2 ), the vertical stresses on key rock block B mainly include the supporting forces from the overlying load, dead load, narrow coal pillars, and immediate roof above physical coal wall, as well as the hinging stress among key rock blocks. Narrow coal pillars, physical coal wall, and roof of surrounding rock are at the plastic zone and should be strengthened by supporting technologies. At the roof, a high-strength anchor supporting technology should be used to reinforce the multilayer immediate roof and form a composite beam. The anchor length should be increased to ensure synchronous movement of immediate and main roofs and protect the supporting effect of anchor rods. The supporting technologies for narrow coal pillars and physical coal seam are the same as those in scheme 1. The supporting technology to narrow coal pillar goaf during the working face recovery in the last working face should be enhanced to reduce the large deformation area in the narrow coal pillar goaf. Real-time preload monitoring is necessary to ensure supporting strength of anchor rod (cable).

(3) With respect to the stress-strain features of surrounding rock under a high main roof height (scheme 3 ), the stresses on key rock block B are similar to those in scheme 2. Therefore, key attention should be provided to reinforce support to narrow coal pillars, roof, and physical coal wall. Except for the combined supporting technologies of anchor rod (cable), ladder beam, and $\mathrm{W}$ steel, the anchor rod (cable) should be equipped with a large initial preload to offer positive support and increase the overall strength of surrounding rock.

\subsection{Engineering Application Analysis}

The rail transport roadway of the 8105 working face advances along the 8104 goaf. The setting-up width of narrow coal pillar is $6.0 \mathrm{~m}$. Supporting parameters are introduced in references $[6,16]$ and are shown in Fig. 8. The roof anchor rob is $\varnothing \times L=20 \times 2200 \mathrm{~mm}$, with a preload no lower than $100 \mathrm{kN}$. The anchor cable at two sides is $\varnothing \times L=18 \times 2200 \mathrm{~mm}$, with a preload no lower than $80 \mathrm{kN}$. The roof anchor cable is $\varnothing \times L=17.8 \times 6200$ $\mathrm{mm}$, and the anchor cable at two sides is $\varnothing \times L=17.8 \times$ $4200 \mathrm{~mm}$, with a preload no lower than $130 \mathrm{kN}$. After the 
roadway advances for 20 days, the surrounding rock is basically stable, and the maximum displacements at rooffloor and two sides are 118 and $65 \mathrm{~mm}$, respectively. The preload of anchor rod (cable) is regularly tested before the influence of the working face recovery is induced, but no supporting failure is discovered.

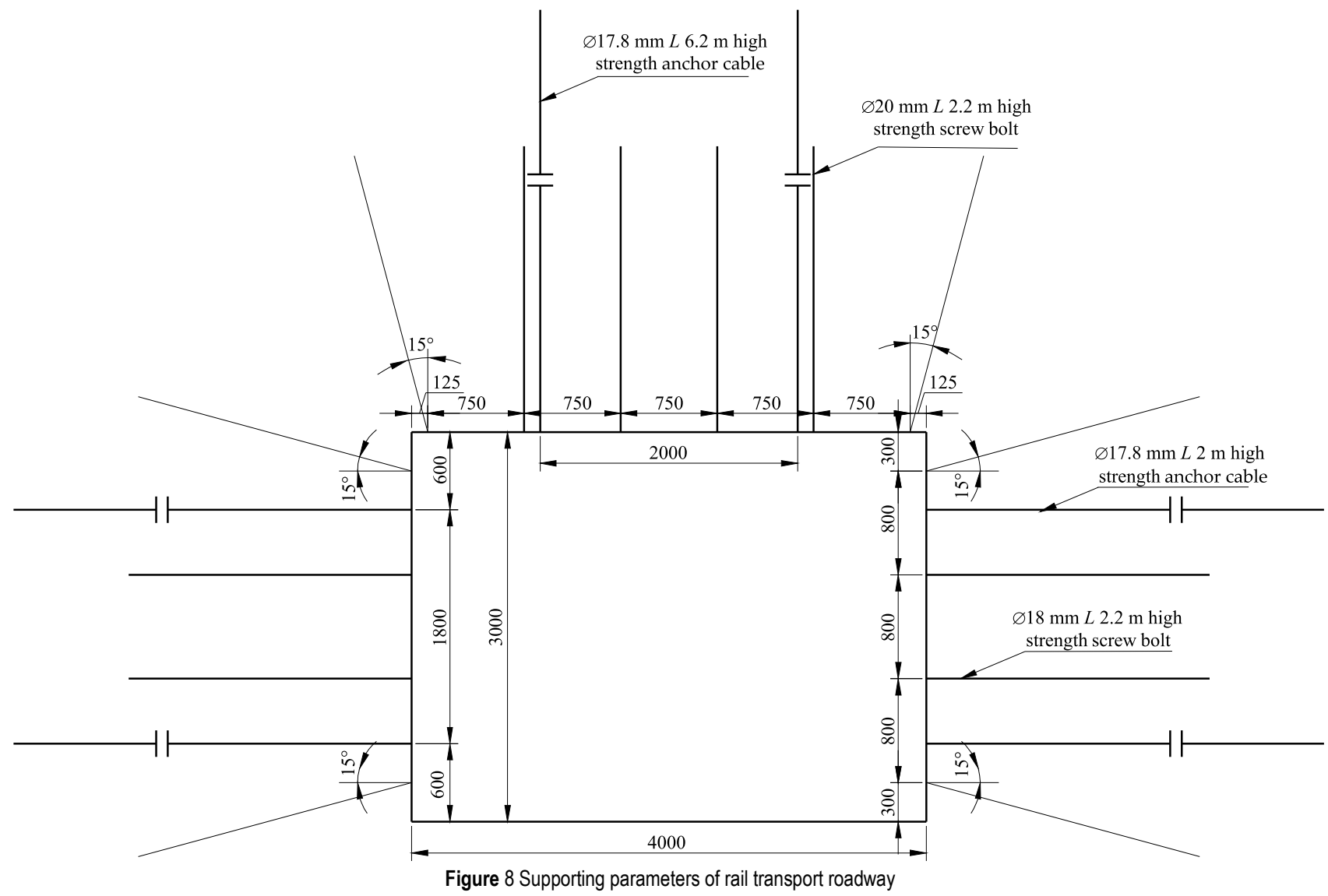

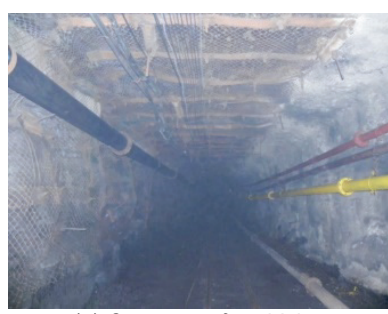

(a) One year after driving

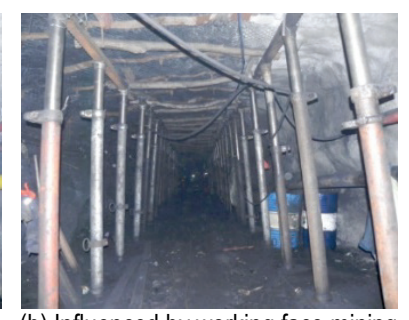

(b) Influenced by working face mining

Figure 9 Control effects of the surrounding rocks of the 8105 working face

When the working face is mined, the maximum rooffloor relative deformation and the maximum relative deformation at two sides are $200 \mathrm{~mm}$ to $420 \mathrm{~mm}$ and 380 $\mathrm{mm}$ to $600 \mathrm{~mm}$, respectively. The control effects of the surrounding rocks of roadway are shown in Fig. 9. The deformation of surrounding rock is similar to that in scheme 3 . The supporting technologies achieve satisfying economic benefits.

\section{CONCLUSIONS}

A mechanical model of the surrounding rock of gob-side entry driving in a fully-mechanized top-coal caving working face was established to explore the influence mechanism of main roof height on the stability of the surrounding rock structure of gob-side entry driving. The stress and deformation distribution characteristics of the surrounding rock were analyzed by using UDEC2D4.0. The following conclusions are drawn.
(1) With the change in main roof heights, key rock block B first produces four contact methods with the waste rocks in the caving zone and the damaged immediate roof and then four stress combinations, which affect the stability of the surrounding rock of gob-side entry driving.

(2) With the increase in main roof height, the hinged stress between key rock blocks and the plastic damage area of the physical coal wall are reduced, and the damage range of immediate roof is gradually increased. The large deformation regions at the narrow coal pillar goaf and the angle of "shear failure line" gradually expand. The vertical stress of narrow coal pillars and the relative deformations of surrounding rock first increase and then gradually stabilize.

(3) With the increase in main roof height, the supporting strength of roof and physical coal wall should be enhanced, and the passive support is changed into positive support. Anchor cable length should be increased to transmit concentrated stress to deep places of the surrounding rock, and the supporting condition is regularly monitored in this process.

(4) The engineering application effect demonstrates that anchor rod (cable) exerts a good supporting effect, and supporting technologies can timely change passive into positive support. The maximum relative deformation of roadway is $600 \mathrm{~mm}$ and achieves satisfying economic benefits. 
Thus, the key supporting technology can be easily adjusted according to the change in the main roof height, and this technology can effectively control the deformation of surrounding rock. Such a technology is technically feasible and provides theoretical support for the stability of the surrounding rock of gob-side entry driving. However, many parameters are simplified in the process of establishing mechanical models and numerical models, and the number of mine applications is small, so the deformation indexes of surrounding rock are limited. Other remaining main roof heights should be further studied in actual conditions.

\section{Acknowledgement}

This study was supported by the National Natural Science Foundation of China (51327007, 51734007, 51674192, 51774235, 51704227).

\section{REFERENCES}

[1] Feng, X. W., Zhang, N., Chen, X. T., Gong, L. Y., Lv, C. X., Guo, Y. (2016). Exploitation contradictions concerning multi-energy resources among coal, gas, oil, and uranium: A case study in the ordos basin (Western North China Craton and Southern Side of Yinshan Mountains). Energies, 9(2), 119-134. https://doi.org/10.3390/en9020119

[2] Vakili, A. \& Hebblewhite, B. K. (2010). A new cavability assessment criterion for longwall top coal caving. International Journal of Rock Mechanics and Mining Sciences, 47(8), 1317-1329. https://doi.org/10.1016/j.jirmms.2010.08.010

[3] Zhang, Z. Z., Bai, J. B., Chen, Y., \& Yan, S. (2010). An innovative approach for gob-side entry retaining in highly gassy fully-mechanized longwall top-coal caving. International Journal of Rock Mechanics and Mining Sciences, 80, 1-11. https://doi.org/10.1016/j.jirmms.2015.09.001

[4] Małkowski, P., Ostrowski, Ł., \& Bachanek, P. (2017). The impact of the low throw fault on the stability of roadways in a hard coal mine. Studia Geotechnica et Mechanica, 39(1), 63-72. https://doi.org/10.1515/sgem-2017-0006

[5] Coggan, J., Gao F. Q., Stead D., \& Elmo D. (2001). Numerical modelling of the effects of weak immediate roof lithology on coal mine roadway stability. International Journal of Coal Geology, 90, 100-109.

[6] Shuang, H. Q. Study on stability analysis and control technology about roadway driving along goaf at fully mechanized top coal caving. M.S. Thesis of Xi'an University of Science and Technology, Shanxi, China, 2015.

[7] Kang, H. P. (2014). Support technologies for deep and complex roadways in underground coal mines: a review. International Journal of Coal Science and Technology, 1(3), 261-277. https://doi.org/10.1007/s40789-014-0043-0

[8] Hou, C. J. \& Li, X. H. (2001). Stability principle of big and small structures of rock surrounding roadway driven along goaf in fully mechanized top coal caving face. Journal of China Coal Society, 26(1), 1-7.

[9] Bai, J. B., Shen, W. L., Guo, G. L., Wang, X. Y., \& Yu, Y. (2015). Roof deformation, failure characteristics, and preventive techniques of gob-side entry driving heading adjacent to the advancing working face. Rock Mechanics and Rock Engineering, 48(6), 2447-2458. https://doi.org/10.1007/s00603-015-0713-2

[10] Bai, J. B. (2006). Control mechanism about gateway driven along goaf. China University of Mining and Technology press, Xuzhou.

[11] Feng, X. W. \& Zhang, N. (2015). Position-optimization on retained entry and backfilling wall in gob-side entry retaining techniques. International Journal of Coal Science and Technology, 2(3), 186-195.

https://doi.org/10.1007/s40789-015-0077-y

[12] Li, Y. F., Hua, X. Z., \& Cai, R. C. (2012). Mechanics analysis on the stability of key block B in the gob-Side entry retaining and engineering application. Journal of Mining and Safety Engineering, 29(3), 357-364.

[13] Zhang, N., Yuan, L., Han, C. L., Xue, J. H., \& Kan, J. J. (2012). Stability and deformation of surrounding rock in pillarless gob-side entry retaining. Safety Science, 50(4), 593-599. https://doi.org/10.1016/j.ssci.2011.09.010

[14] Li, L., Bai, J. B., Xu, Y., Xiao, T. Q., Wang, X. Y., Zhang, K. X. (2011). Research on rock control of roadway with complex roof driven along goaf. Journal of Mining and Safety Engineering, 28(3), 376-383.

[15] Wang, M., Bai, J. B., Li, W., Wang, X. Y., \& Cao, S. G. (2015). Failure mechanism and control of deep gob-side entry. Arabian Journal of Geosciences, 8(11), 9117-9131. https://doi.org/10.1007/s12517-015-1904-6

[16]Wang, H. S., Zhang, D. S., Li, S. G., Wang, L., \& Wu, L. Z. (2014). Rational width of narrow coal pillar based on the fracture line location of key rock B in main roof. Journal of Mining and Safety Engineering, 31(1), 10-16.

[17] Su, H., Bai, J. B., Yan, S, Chen, Y., \& Zhang, Z. Z. (2015). Study on gob-side entry retaining in fully-mechanized longwall with top-coal caving and its application. International Journal of Mining Science and Technology, 25(3), 503-510. https://doi.org/10.1016/j.jimst.2015.03.027

[18] Yang, H. Y., Cao, S. G., Li, Y., Sun, C. M., \& Guo, P. (2015). Soft roof failure mechanism and supporting method for gob-side entry retaining. Minerals, 5(4), 707-722. https://doi.org/10.3390/min5040519

[19] Qian, M. G., Miao, X. X., \& He, F. L. (1994). Analysis of key block in the structure of voussoir beam in longwall mining. Journal of China Coal Society, 19(6), 557-563.

[20] Yang J. P., Cao S. G., \& Li X. H. (2013). Failure laws of narrow pillar and asymmetric control technique of gob-side entry driving in island coal face. International Journal of Mining Science and Technology, 23(2), 267-272.

https://doi.org/10.1016/j.jmst.2013.04.008

\section{Contact information:}

\section{Haiqing SHUANG, Ph.D.}

Institution:

College of Safety Science and Engineering, Xi'an University of Science and

Technology, Xi'an 710054, P. R.China

Postal address:

Room 1501, College of Mechanical and Electrical Engineering, China University of Mining \& Technology, No.58 Yan Ta Road, Xi'an, 710054, Shaanxi Province, P. R. China.

ZIP code: 710054

E-mail: shuanghaiqing@163.com

Shugang LI, Ph.D., Professor (Corresponding author)

Institution:

College of Safety Science and Engineering, Xi'an University of Science and

Technology, Xi'an 710054, P. R.China

Postal address:

Room 1501, College of Mechanical and Electrical Engineering, China University of Mining \& Technology, No.58 Yan Ta Road , Xi'an, 710054, Shaanxi Province, P. R. China.

ZIP code: 710054

E-mail: lisg63@163.com

\section{Gaofeng CHEN, M.S}

Institution:

College of Safety Science and Engineering, Xi'an University of Science and Technology, Xi'an 710054, P. R.China

Postal address: 
Room 1501, College of Mechanical and Electrical Engineering, China University of Mining \& Technology, No.58 Yan Ta Road , X'an, 710054, Shaanxi Province, P. R. China.

E-mail: chengaof110@163.com

Peng XIAO, Ph.D., Associate Professor

Institution:

College of Safety Science and Engineering, Xi'an University of Science and

Technology, Xi'an 710054, P. R.China

Postal address:

Room 1501, College of Mechanical and Electrical Engineering, China University of Mining \& Technology, No.58 Yan Ta Road , Xi'an, 710054, Shaanxi Province, P. R. China.

E-mail: xiaopeng@xust.edu.cn

\section{Liangchang SHEN, B.S.}

Institution:

College of Energy Engineering, X'an University of Science and Technology,

Xi'an 710054, P. R.China

Postal address:

Room 9605, College of Energy Engineering, China University of Mining \&

Technology, No.58 Yan Ta Road, Xi'an, 710054, Shaanxi Province, P. R. China

E-mail: 18992285113@163.com

Ki-il SONG, Ph.D., Associate Professor

Institution:

Department of Civil Engineering, Inha University, Incheon 402-751, Korea

Postal address:

Department of Civil Engineering, Inha University, 100 Inha-ro, Nam-gu, Incheon

402-751, Republic of Korea

E-mail: ksong@inha.ac.kr 